\title{
The Activity of Topical Coenzyme Q10 (Ubiquinol) In Burned Rats: Results From An Experimental Study
}

\author{
Ceren Canbey Göret ${ }^{1^{*}}$, Aslı Kiraz ${ }^{2}$, Nuri Emrah Göret ${ }^{3}$, Sevilay Oğuz Kılıç ${ }^{4}$, Ömer Faruk Özkan ${ }^{5}$, \\ Muammer Karaayvaz ${ }^{6}$
}

${ }^{1}$ Department of Surgical Pathology, Health Sciences University, Sancaktepe Research and Education Hospital, Istanbul, Turkey

${ }^{2}$ Departments of Microbiology, Onsekiz Mart University Research and Application Hospital, Canakkale, Turkey

${ }^{3}$ Department of General Surgery, Health Sciences University, Kartal Dr Lütfi Kirdar Research and Education Hospital, Istanbul, Turkey

${ }^{4}$ Department Dermatology, Onsekiz. Mart University Research and Application Hospital, Canakekale, Turkey

${ }^{5}$ Department of General Surgery, Health Sciences University, Umraniye Research and Education Hospital, Istanbul,

Turkey

${ }^{6}$ Department General Surgery, Onsekiz, Mart University Research and Application Hospital, Canakkale, Turkey

\begin{abstract}
The objective of this study was to investigate the effectiveness of topically applied coenzyme Q10 (CoQ10) (ubiquinol) for wound healing in rats with experimentally induced burn injuries.

A total of 27 rats were divided into three groups, and administered general anesthesia. No further intervention was performed for Group 1 (Control). Hot water $\left(95^{\circ} \mathrm{C}\right)$ was applied to rats in Groups 2 and 3 for 10 seconds. The rats in Group 2 received silver sulfadiazine, whereas those in Group 3 received topical CoQ10. Biopsy samples were obtained at days 3 and 10 .

In the group treated with CoQ10 (Group 3), there was no statistically significant difference among between Days 3 and 10 in terms of inflammation and epidermal/vascular/collagen damage. In terms of edema, there was a statistically significant distinction among the CoQ10 group (Group 3) at Day 10 and the silver sulfadiazine group (Group 2) at Day 3. In terms of oxygen radicals, there was a statistically meaningful difference among the CoQ10 group and the silver sulfadiazine group at Day 10.

This investigation did not demonstrate a beneficial role of treatment with CoQ10 for the healing of burn wounds for most parameters. But in the long term (10 day); immunohistochemical analysis performed to determine edema and oxidative stress showed that treatment with CoQ10 reduced the levels of oxygen radicals in biopsies. The limitation of our study is that the duration is limited to 10 days. For this reason longer term studies were required.
\end{abstract}

Key Words: Topical coenzyme Q10, burn, wound healing, rats, free oxygen radicals

\section{Introduction}

Burn is a type of tissue loss caused by heat, electricity, chemical materials, or radiation exposure. Despite lacking a reliable database in Turkey, it is reported that $\sim 11$ million people worldwide require medical treatment for burn injuries (1-4).

Burn injuries are characterized by substantial loss of liquids, electrolytes, proteins, and minerals due to disrupted skin barrier functions. Additionally, ongoing processes (e.g., severe catabolism, infection, and wound healing) are linked to an increased demand for nutrients.
The wound-healing process comprises three main interconnected phases, the exudative or inflammatory phase (3 days), proliferative phase (approximately 10 days), and regenerative phase (approximately 2 years) (5-7). Wound healing aims to minimize tissue damage and ensure sufficient tissue perfusion and oxygenation. During this process, the production of reactive oxygen species is important for preventing infection. However, its excessive production may cause oxidative stress, impeding the wound healing process $(8,9)$.

Coenzyme Q10 (CoQ10) is a vitamin-like, fatsoluble, antioxidant molecule that is important in the mitochondrial respiratory chain. It promotes 


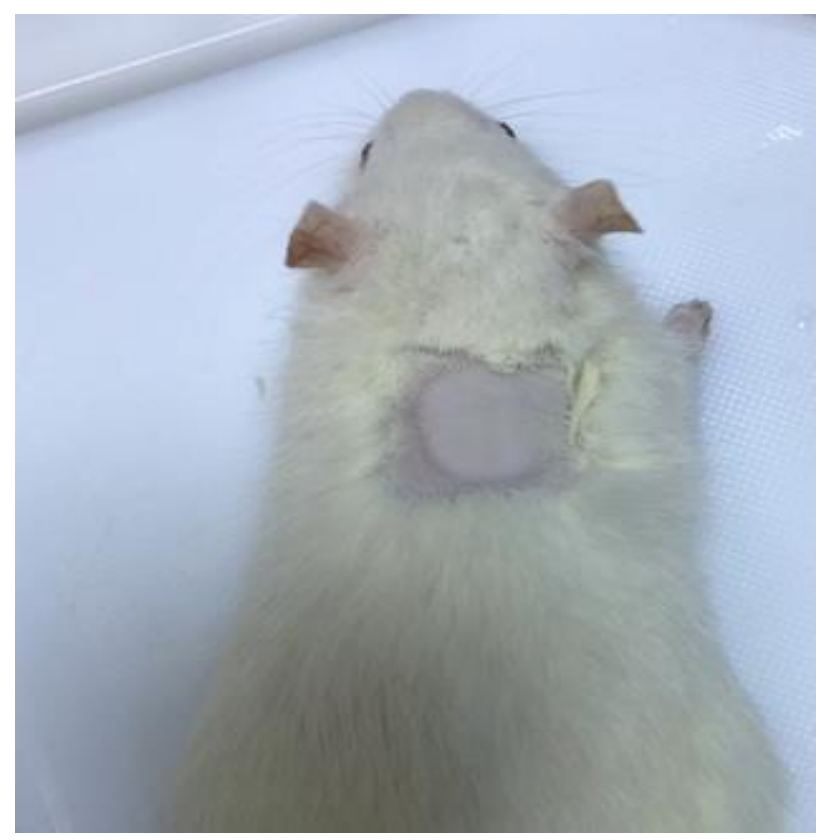

Fig. 1. The area of burn injury experimentally induced by exposing to hot water at $95^{\circ} \mathrm{C}$ for $10 \mathrm{~s}$

tissue healing by reducing oxidative stress and increasing mitochondrial functioning. A study on rats revealed that $\mathrm{CoQ} 10$ increases collagen synthesis in wound tissues (10).

Currently, there is an unmet medical need for the effective treatment of burn injury patients, and further studies in this area are warranted. Data from studies investigating the effectiveness of CoQ10 in this setting are limited.

Herein, we investigated the effectiveness of topically applied CoQ10 for wound healing in rats with experimentally induced burn injuries.

\section{Materials and Methods}

Chemicals: Silver sulfadiazine; Silverdin $\AA$, Deva Drug Corporation.

Ketamine; Ketalar; Pfizer Drug Corporation.

Xylazine; Kepro Xylazine; Biopharm Drug Corporation.

CoQ10 (ubiquinol); Solgar Ubiquinol Reduced CoQ10, $100 \mathrm{mg} 50$ Softgels.

Experimental protocol: All rats used in this study were provided from the Animal Research Station of Canakkale Onsekiz Mart University, Turkey. The animals were housed in special metal lattices at room temperature under stable environmental terms $\left(21^{\circ} \mathrm{C} \pm 2^{\circ} \mathrm{C}\right.$ and 12 hour dark- 12 hour light cycles). Albino Wistar rats weighing 220-250 $\mathrm{g}$ were separated into three groups. All rats were anesthetized with xylazine and ketamine. -Group 1A (Day 3); Group 1B (Day 10); (Control group);

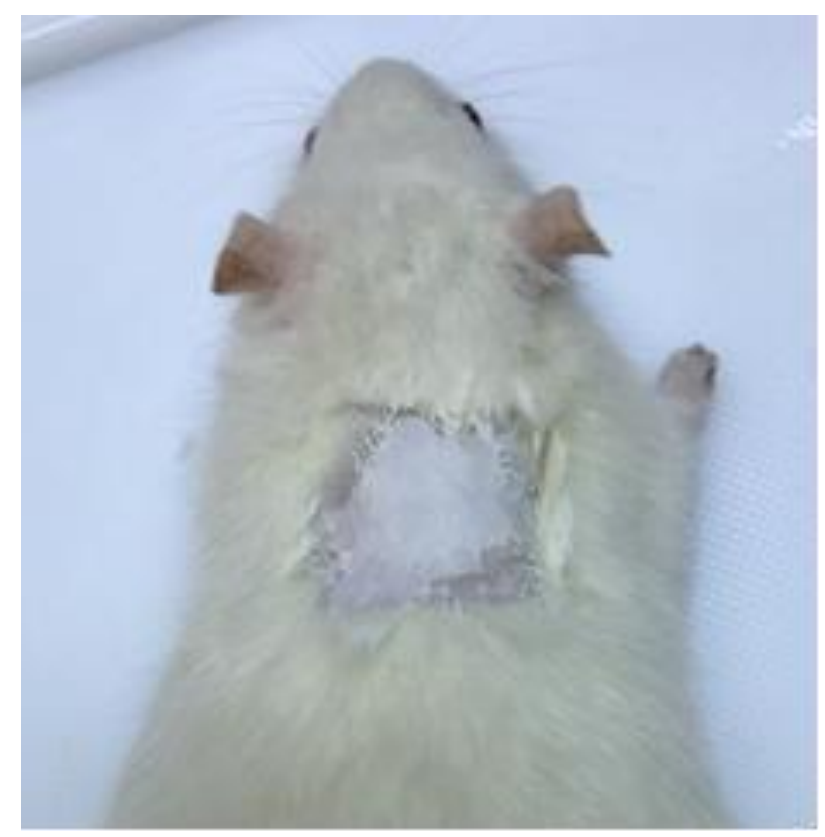

Fig. 2. Silver sulfadiazine implementation to the burned area

The back of the rats was shaved under anesthesia, no further intervention was performed. Biopsy samples for histopathologic analysis were obtained from the shaved area under general anesthesia at Days 3 and 10. Subsequently, the rats were sacrificed.

-(Group 2A (Day 3); Group 2B (Day 10); (Silver sulfadiazine group); The back of the rats was shaved under anesthesia, and hot water $\left(95^{\circ} \mathrm{C}\right)$ was applied to the shaved area for 10 seconds (Fig. 1). Subsequently, the rats were wrapped with a cold towel and $8 \mathrm{ml}$ of Ringer's lactate were applied intraperitoneally to avoid burn shock. Silver sulfadiazine was applied topically to the burn wounds daily (Fig. 2). Biopsy samples for histopathologic analysis were obtained from the injured tissues under general anesthesia at Days 3 and 10 . Subsequently, the rats were sacrificed.

-Group 3A (Day 3); Group 3B (Day 10); (CoQ10 group); The back of the rats was shaved under anesthesia and hot water $\left(95^{\circ} \mathrm{C}\right)$ was applied to the shaved area for 10 seconds. Subsequently, the rats were wrapped with a cold towel, and $8 \mathrm{ml}$ of lactated Ringer's solution were administered intraperitoneally to avoid burn shock. A sterile derivative of CoQ10 $10 \mathrm{mg} / \mathrm{kg}$ prepared with saline solution was applied topically to the burn wounds daily (Fig. 3). Biopsy samples for histopathologic analysis were obtained from the injured tissue under general anesthesia at Days 3 and 10. Subsequently, the rats were sacrificed.

All groups on the $3^{\text {th }}$ day, B groups represent biopsies sampled on day 10 . 


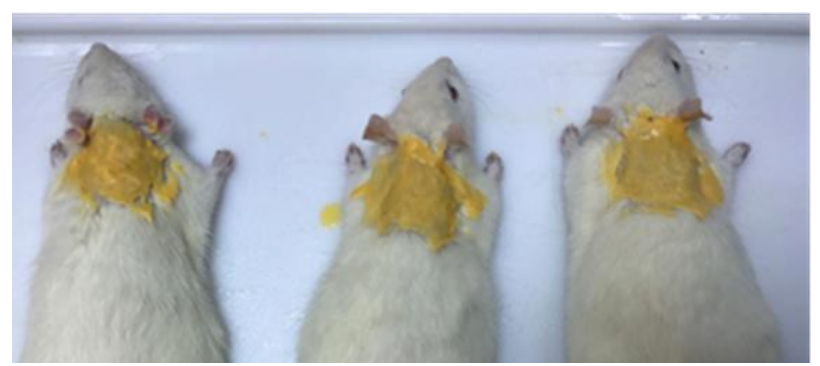

Fig. 3. CoQ10 implementation to the burned area

Histopathological study: All samples were put into buffered formaldehyde. Samples embedded in paraffin blocks were stained with hematoxylin and eosin ( $\mathrm{H} \& \mathrm{E}$ ) using 5-6 $\mu \mathrm{m}$ thick sections. Additionally H\&E, immunohistochemicaly analyses were done using glutathione S-transferase (GSTP 1), glutathione reductase (Glut-Red), superoxide dismutase (SOD-1), and catalase (CAT). Dako kits and staining device were used to stain 2-4 $\mu \mathrm{m}$ thickness sections from paraffin blocks (Fig. 4-6).

Parameters such as edema, inflammation, epidermal damage, vascular damage, and collagen damage were evaluated histopathologically (Table 1).

The effects of the treatment on these parameters were studied using the following scale: $0=$ None effect; 1 = Minor effect; $2=$ Important effect; $3=$ Intense effect.

Staining using GSTP-1, CAT Glut Red, and SOD1 was evaluated using the following scale: $0=$ no staining; 1 = weak positivity; 2 = moderate positivity; 3 = strong positivity.

Statistical analysis: Data were analyzed using the Statistical Package for Social Sciences version 20, Chicago, IL, USA. Normality of continuous data was determined by the Kolmogorov-Smirnov test. Parametric and non-parametric Mann-Whitney U and Kruskal-Wallis tests were conducted. Data are expressed as means \pm standard deviations. Twotailed $\mathrm{p}$ values $<0.05$ were considered to be statistically significant. The Bonferroni test was used for differences among groups. A $\mathrm{p}<0.05$ point out statistical significance.

\section{Results}

The statistical analyses showed that the results of samples from all groups were not normally distributed. Therefore, the Kruskal-Wallis test was used for comparisons. All parameters were valudated using the Mann Whitney $\mathrm{U}$ test. The asymptomatic sign value between groups $1 \mathrm{~A}-1 \mathrm{~B}-$ $2 \mathrm{~A}-2 \mathrm{~B}-3 \mathrm{~A}-3 \mathrm{~B}$ for each parameter was $\mathrm{p}=0.001$

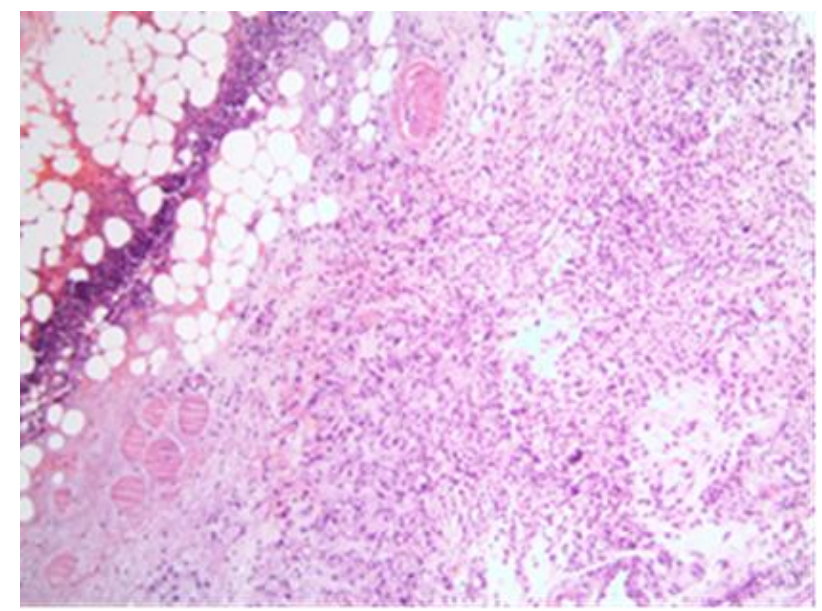

Fig. 4. Violent score 3 inflammation in the burn injured tissue $(\mathrm{H} \& \mathrm{E} \times 400)$

$(\mathrm{p}<0.05)$; denoting a statistically significant difference among all groups.

$\mathrm{P}<0.05$, pair-group analysis was valuation by the Mann-Whitney $U$ test and each immunohistochemical marker was individually scored. However, statistical valuation was performed for each rat on the basis of the total score.

Pair-group analysis: There was a statistically significant difference between group 1 and all other groups in terms of all parameters (edema, inflammation, epidermal damage, vascular damage, and collagen damage).

There was no statistically significant difference between the parameters of group 2 and group 3.

Only in terms of edema, there was a statistically significant difference between the group 3 (CoQ10) at Day 10 and the group 2 (silver sulfadiazine group) at Day 3; and there was a statistically significant difference between the group 3 (CoQ10 group) and the group 2 (silver sulfadiazine group) at Day 10.

P-values are summarized in table 2 according to histopathological parameters in study groups (Table 2).

\section{Discussion}

CoQ10 is an oil-soluble antioxidant used as antiaging and anti-wrinkle agent in cosmetic (7-11). Oxygen species are produced in cutaneous injury. Thus it may be beneficial to protect cells from reactive oxygen species-induced damage through improving local antioxidant activity in wounds (10).

It is known that several numerous markers such as matrix metalloproteinases, SOD-1, CAT, reduced 


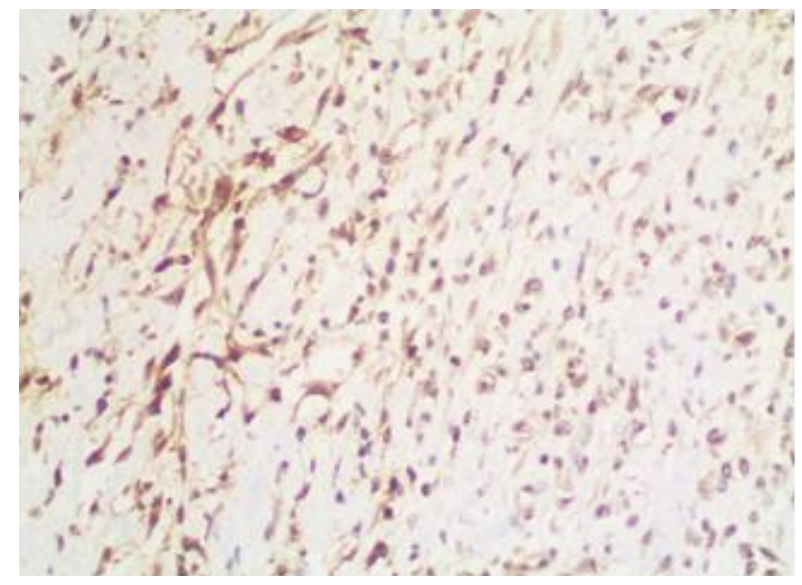

Fig. 5. Powerful score 3 positivity with CAT (immunohistochemistry $\times 400$ )

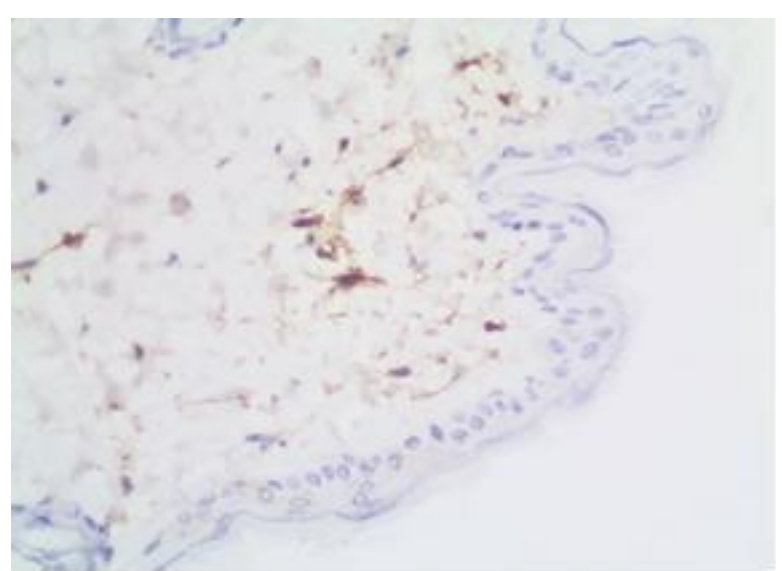

Fig. 6. Moderate score 2 staining with GSTP 1 (immunohistochemistry x 400)

Table 1. Histopathological scoring table

\begin{tabular}{ccccccc}
\hline Score & Edema & Inflammation & $\begin{array}{c}\text { Vascular } \\
\text { damage }\end{array}$ & $\begin{array}{c}\text { Collagen } \\
\text { damage }\end{array}$ & $\begin{array}{c}\text { Epidermal } \\
\text { Damage }\end{array}$ & $\begin{array}{c}\text { SOD1 CAT GSTP1 } \\
\text { GLUT-RED } \\
\text { (Immunohistochemistry) }\end{array}$ \\
\hline 0 & None & None & None & None & None & No staining \\
1 & Minor & Minor & Minor & Minor & Minor & Weak positivity \\
2 & Important & Important & Important & Important & Important & Moderate positivity \\
3 & Intense & Intense & Intense & Intense & Intense & Strong positivity \\
\hline
\end{tabular}

glutathione, malondialdehyde, myeloperoxidase, vascular endothelial growth factor, hydroxyproline, hexosamine, and ascorbic acid are involved in the healing process of burn wounds (11-13).

In vitro models for studies investigating experimental burn injuries are limited. Moreover, the use of animal models is essential for this research. Rats are a frequently used animal model for studies investigating experimental burn injuries. Various techniques including direct contact with a heated metal, electricity, and heated water have been used in experimental animal models. Among those, the hot water model is the most commonly used and considered as the standard method for animal models of burn injuries (6). We implemented the hot water method in this study and it was based on the method described previously by Allgöwer et al, with a slight modification (11).

The CoQ10 is a lipophilic molecule with large molecular weight (14). Consequently, the efficacy of gastrointestinal administration of CoQ10 is poor.

Furthermore, the bioavailability of topical CoQ10 is poor, and new topical formulations such as liposomal CoQ10 have recently been developed to improve bioavailability. Lee and Tsai, using an experimental rat model, reported that topical administration of liposomal CoQ10 improved bioavailability and indicated that penetration of CoQ10 was dependent on concentration (15). The investigators also found that long-term exposure of skin to CoQ10 resulted in improved skin penetration. In the present study, liposomal CoQ10 was used.

Immunohistochemical analysis to determine oxidative stress showed that there was a statistically significant difference between the biopsy samples obtained at Day 10 in terms of GSTP-1, CAT, Glut Red, and SOD-1 activity. Moreover, it was observed that the levels of free oxygen radicals in the biopsies were higher in the CoQ10 group compared with the silver sulfadiazine group. 
Table 2. P-values in the study groups according to histopathological parameters $(\mathrm{P}<0.05)$

\begin{tabular}{|c|c|c|c|c|c|c|}
\hline Groups & Edema & inflammation & $\begin{array}{l}\text { Vascular } \\
\text { damage }\end{array}$ & $\begin{array}{l}\text { Collagen } \\
\text { damage }\end{array}$ & $\begin{array}{c}\text { Epidermal } \\
\text { Damage }\end{array}$ & $\begin{array}{l}\text { Immunohistochemistry } \\
\text { score for free oxygen } \\
\text { radicals }\end{array}$ \\
\hline Group 1A-2A & 0,001 & 0,001 & 0,001 & 0,001 & 0,001 & 0,001 \\
\hline Group 1A-3A & 0,001 & 0,001 & 0,001 & 0,001 & 0,001 & 0,001 \\
\hline Group 1A-1B & 0,436 & 0,730 & 0,998 & 0,998 & 0,998 & 0,161 \\
\hline Group 1A-2B & 0,001 & 0,001 & 0,001 & 0,001 & 0,001 & 0,001 \\
\hline Group 1A-3B & 0,001 & 0,001 & 0,001 & 0,001 & 0,001 & 0,001 \\
\hline Group 2A-3A & 0,258 & 0,863 & 0,796 & 0,161 & 0,340 & 0,730 \\
\hline Group $2 \mathrm{~A}-1 \mathrm{~B}$ & 0,001 & 0,001 & 0,001 & 0,001 & 0,001 & 0,001 \\
\hline Group 2A-2B & 0,094 & 0,161 & 0,222 & 0,113 & 0,998 & 0,222 \\
\hline Group $2 \mathrm{~A}-3 \mathrm{~B}$ & 0,730 & 0,666 & 0,796 & 0,113 & 0,340 & 0,136 \\
\hline Group 3A-1B & 0,001 & 0,001 & 0,001 & 0,001 & 0,001 & 0,001 \\
\hline Group 3A-2B & 0,006 & 0,077 & 0,113 & 0,730 & 0,340 & 0,011 \\
\hline Group 3A-3B & 0,436 & 0,436 & 0,998 & 0,730 & 0,998 & 0,031 \\
\hline Group 1B-2B & 0,001 & 0,001 & 0,001 & 0,001 & 0,001 & 0,001 \\
\hline Group 1B-3B & 0,001 & 0,001 & 0,001 & 0,001 & 0,001 & 0,001 \\
\hline Group 2B-3B & 0,040 & 0,297 & 0,113 & 0,998 & 0,340 & 0,001 \\
\hline
\end{tabular}

Collagen is the main structural component of the connective tissue and known to improve the healing process. It has been shown to increase vascularization during repair of connective tissue and damaged tissues (16). Kiyan et al. conducted a study using rats with Hypericum perforatuminduced burn injuries (5). The investigators suggested that wound healing may be the result of fibroblast migration and stimulation of collagen synthesis.

Studies have also reported that fibroblasts decrease the levels of antioxidants (17). Damage to the skin triggers edema and inflammatory cell infiltration (18-20). This may lead to disruption of the antioxidant balance, damages to cellular proteins and lipids, DNA oxidation, and elevate in the levels of free oxygen radicals at the cellular level $(21,22)$.

Based on the most parameters evaluated in the present study, CoQ10 was not superior to silver sulfadiazine. This may be due to insufficient penetration of topically applied CoQ10 into the injured tissue or have a short duration (10 days).

In conclusion: This investigation did not demonstrate a serious beneficial role of treatment with CoQ10 for the healing of burn wounds.

However in the long term (10 days), immunohistochemical analysis performed to determine edema and oxidative stress showed that treatment with CoQ10 reduced the levels of free oxygen radicals in biopsies.

The limitation of our study is that the duration is limited to 10 days. For this reason longer term studies were required.

This study was done in the animal laboratory of University of Onsekiz Mart, Research / Application Center, Turkey, and permission received from the Laboratory Ethics Committee (No:2017 / 3744). And this study presented as a poster 21. National Surgery Congress, Antalya/Turkey (EPS-0961) 


\section{References}

1. Zor F, Ersoz N, Kulahci Y, Kapi E, Bozkurt M. Gold standards for primary care of burn management. Dicle Med J 2009; 36: 219-225.

2. Opara KO, Chukwuanukwu TO, Ogbonnaya IS, Nwadinigwe CU. Pattern of severe electrical injuries in a Nigerian regional burn centre. Niger J Clin Pract 2006; 9: 124-127.

3. Argenta A, Demos J. Burn Management in the Developing World. International Volunteerism. Clin Plastic Surg 2017; 44: 875883.

4. Gumus N. Negative pressure dressing combined with a traditional approach for the treatment of skull burn. Niger J Clin Pract. 2012; 15: 494-497.

5. Kıyan S, Uyanıkgil Y, Altuncı YA, Çavuşoğlu T, Çetin Uyanıkgil EÖ, Karabey F. Investigation of acute effects of Hypericum perforatum (St. John's Wort-Kantaron) treatment in experimental thermal burns and comparison with silver sulfadiazine treatment. Ulus Travma Acil Cerrahi Derg 2015; 21: 323336.

6. Abdullahi A, Amini-Nik S, Jeschke MG. Animal models in burn research. Cell Mol Life Sci 2014; 71: 3241-3255.

7. Moir J, Serra MP. The use of silver nitrate in wound management. Ann Ital Chir 2012; 83: 45-48.

8. Yoneda T, Tomofuji T, Kawabata Y, Ekuni D, Azuma T, Kataoka K, et al. Application of coenzyme Q10 for accelerating soft tissue wound healing after tooth extraction in rats. Nutrients 2014; 6: 5756-5769.

9. Prisăcaru AI, Andriţoiu CV, Andriescu C, Hăvârneanu EC, Popa M, Motoc AG, et al. Evaluation of the wound-healing effect of a novel Hypericum perforatum ointment in skin injury. Rom J Morphol Embryol 2013; 54(4): 1053-1059.

10. Choi BS, Song HS, Kim HR, Park TW, Kim TD, Cho BJ, et al. Effect of coenzyme Q10 on cutaneous healing in skin-incised mice. Arch Pharm Res 2009; 32: 907-913.

11. Allgöwer M, Schoenenberger GA, Sparkes BG. Burning the largest immune organ. Burns 1995; 21: 7-47.

12. El-Leithy ES, Makky AM, Khattab AM, Hussein DG. Optimization of nutraceutical coenzyme Q10 nanoemulsion with improved skin permeability and anti-wrinkle efficiency. Drug Dev Ind Pharm 2017; 2: 1-13.

13. Bahramsoltani R, Farzaei MH, Rahimi R. Medicinal plants and their natural components as future drugs for the treatment of burn wounds: an integrative review. Arch Dermatol Res 2014; 306: 601-617.

14. Bhagavan HN, Chopra RK. Coenzyme Q10: absorption, tissue uptake, metabolism and pharmacokinetics. Free Radic Res 2006; 40: 445-453.

15. Lee WC, Tsai TH. Preparation and characterization of liposomal coenzyme Q10 for in vivo topical application. Int J Pharm 2010; 395: 78-83.

16. Chvapil M, Chvapil TA, Owen JA. Reaction of various skin wounds in the rat to collagen sponge dressing. J Surg Res 1986; 41: 410-418.

17. Awonuga AO, Belotte J, Abuanzeh S, Fletcher NM, Diamond MP, Saed GM. Advances in the pathogenesis of adhesion development: the role of oxidative stress. Reprod Sci 2014; 21: 823-836.

18. Bishop T, Hewson DW, Yip PK, Fahey MS, Dawbarn D, Young AR, et al. Characterisation of ultraviolet-B induced inflammation as a model of hyperalgesia in the rat. Pain 2007; 131: 70-82.

19. Pegoraro NS, Barbieri AV, Camponogara C, Mattiazzi J, Brum ES, Marchiori MCL, et al. Nanoencapsulation of coenzyme Q10 and vitamin $\mathrm{E}$ acetate protects against UVB radiation-induced skin injury in mice. Colloids Surf B Biointerfaces 2017; 150: 32-40.

20. Ozcelik U, Ekici Y, Bircan HY, Aydogan C, Turkoglu S, Ozen O, et al. Effect of Topical Platelet-Rich Plasma on Burn Healing After Partial-Thickness Burn Injury. Med Sci Monit. 2016; 22: 1903-1909.

21. Goret CC, Goret NE, Kiraz A, Ozkan OF, Karaayvaz M. The effect of pycnogenol on lymphatic nodes and adhesion during in a peritoneal adhesion model in rats. Acta Cir Bras 2018; 33: 134-143.

22. Libra S, Pagano D, Curella G, Litrico V, Cancelliere M, Audibert D, et al. Experimental research on the use of deferoxamine in the prevention of renal damage from acute ischemia. Ann Ital Chir 1999; 70: 569-573. 